\title{
Saúde de Mulheres Lésbicas e Bissexuais: Política, Movimento e Heteronormatividade
}

\author{
Lesbian and Bisexual Women's Health: Politics, Movement and Heteronormativity
}

La Salud de Mujeres Lesbianas y Bisexuales: Política, Movimiento y Heteronormatividad

\author{
Isabela Guimarães Alves ${ }^{1}$ \\ Lisandra Espíndula Moreira \\ Marco Aurélio Máximo Prado \\ Universidade Federal de Minas Gerais (UFMG)
}

\begin{abstract}
Resumo
Este artigo objetiva discutir as políticas públicas de saúde voltadas para as mulheres lésbicas e bissexuais no Brasil, em diálogo com as demandas apresentadas pelo movimento em sua história. Percorremos brevemente o histórico de consolidação do movimento lésbico e resgatamos as políticas públicas voltadas para cuidado em saúde dessas mulheres. A partir das análises dos quinze documentos selecionados, buscamos compreender quais os discursos reproduzidos em suas elaborações e seus efeitos nas práticas de cuidado em saúde, e identificamos uma série de entraves em suas efetivas implementações. Refletimos sobre o processo de precarização dos corpos de mulheres lésbicas e bissexuais e as heteronormatividades reproduzidas nesse percurso de luta por direitos, produzindo uma série de invisibilidades dentro do movimento, como a invisibilidade de mulheres bissexuais e de mulheres negras. A análise documental e as mudanças recentes na política brasileira apontam para a necessidade de reformulação no cuidado oferecido a essas mulheres e criação de formas de resistência para manutenção dos direitos conquistados.

Palavras-chave: lesbianidade, bissexualidade, movimentos sociais, políticas públicas, saúde
\end{abstract}

\begin{abstract}
This article aims to discuss the public health policies directed toward lesbian and bisexual women in Brazil, dialoguing with the demands presented by the movement through its trajectory. We briefly presented the lesbian movement consolidation history and revisited the public policies for the healthcare of lesbian and bisexual women. From the analyses of the selected fifteen documents, we intended to comprehend the discourses reproduced on their elaboration and their effects on the healthcare practices, identifying a series of difficulties on the effective implementation of these policies. We pondered over the precarization of the lesbian and bisexual women's bodies and the reproduced heteronormativities along their pursuit for rights, producing a series of invisibilities inside the movement, such as the bisexual or black women invisibility. The documental analysis and the recent changes in Brazilian politics indicate the necessity of modifications in the healthcare provided to those women and the creation of resistance paths in order to maintain the conquered rights.
\end{abstract}

Keywords: lesbians, bisexuality, social movements, public politics, health

\section{Resumen}

Este artículo tiene como objectivo reflexionar acerca de las políticas de salud para mujeres lesbianas y bisexuales en Brasil, en conversacion con las demandas presentadas por el movimiento en su historia. Recorremos brevemente por la historia de consolidación del movimiento lesbiano y rescatamos las políticas públicas de cuidado en salud de mujeres lesbianas y bisexuales. Después de analizar los quince documentos seleccionados, buscamos comprender los discursos reproducidos en sus elaboraciones y sus efectos en las prácticas de cuidado en salud, y desde elles identificamos una serie de obstáculos en sus efectivas implementaciones. Reflejamos sobre el proceso de precarización de los cuerpos de mujeres lesbianas y bisexuales y las heteronormatividades reproducidas en el camino de lucha por derechos, que produjo una serie de invisibilidades dentro del movimiento, como la invisibilidad de mujeres bisexuales y de mujeres negras. El análisis documental y los cambios recientes en la política brasileña indican la necesidad de reformulación en el cuidado ofrecido a esas mujeres y la creación de formas de resistencia para la manutención de los derechos alcanzados.

Palabras clave: lesbianidad, bisexualidad, movimientos sociales, políticas públicas, salud

\footnotetext{
${ }^{1}$ Endereço de contato: Av. Antônio Carlos, 6627, Belo Horizonte, MG. CEP 31270-901. E-mail: alves.isabelag@gmail.com
} 


\section{Introdução}

O presente artigo objetiva discutir as políticas públicas de saúde voltadas para as mulheres lésbicas e bissexuais, compreendendo as tensões que se fizeram presentes na construção dessas políticas e as questões que permanecem sobrepondo barreiras para sua efetiva materialização. Para tal, percorreremos brevemente o histórico do movimento de mulheres lésbicas e bissexuais e as demandas que foram sendo construídas por elas e culminaram na criação de uma série de políticas públicas e cartilhas voltadas para o cuidado em saúde dessa população.

As primeiras questões pontuadas pelas organizações formais de mulheres lésbicas e bissexuais já tinham como pauta principal a saúde dessas mulheres. Queixas como a invisibilidade lésbica nos espaços de cuidado à saúde, o despreparo profissional no momento de atendimento e a consequente evasão dessa população nesses contextos, pertinentes ainda hoje, foram priorizadas desde o início pelo movimento. A partir do diálogo entre ativistas e gestoras de saúde, muitas das demandas levantadas pelas mulheres lésbicas e bissexuais foram aparecendo paulatinamente nas políticas e cartilhas publicadas pelas gestões governamentais de cada época.

Os documentos analisados neste texto datam de 1984 até 2014; desde então, nos anos mais recentes, vivenciamos uma inconstância política no país, com o avanço de movimentos neoconservadores, tornando o cenário econômico e político desfavorável para a expansão de políticas sociais (Machado, Lima, \& Baptista, 2017). O contexto político atual se caracteriza por uma forte ofensiva contra os direitos sociais conquistados nos últimos anos, dificultando ainda mais a garantia de visibilidade e respeito no âmbito da saúde das mulheres lésbicas e bissexuais.

Apesar de demarcarmos o avanço nas conquistas do movimento lésbico e bissexual até o ano de 2014, esse caminho se mostrou cheio de entraves na efetiva implementação das políticas e dos planos nacionais voltados para o cuidado em saúde dessas mulheres. Com base nas análises feitas das próprias políticas em diálogo com os movimentos sociais e as produções acadêmicas sobre o campo, é possível identificar que os avanços nas políticas públicas foram insuficientes para a melhoria no cuidado oferecido às mulheres lésbicas e bissexuais.

A aproximação desses documentos com alguns conceitos butlerianos (Butler, 1999; 2011; 2015) nos permite refletir sobre as heteronormatividades reproduzidas na busca pelo reconhecimento como sujeitas de direito. Butler, em entrevista a Prins e Meijer (2002), ao refletir sobre os corpos abjetos como aqueles que não são sequer imagináveis dentro da inteligibilidade normativa, dá-nos pistas sobre os porquês de determinados corpos serem mais ou menos visíveis e legítimos, aqui especificamente no campo da saúde de mulheres lésbicas e bissexuais. Desse modo, o diálogo com Butler nos possibilita caminhar reflexivamente pela consolidação do movimento lésbico e pela construção das políticas públicas de saúde voltadas para essas mulheres.

\section{Notas sobre o Movimento de Mulheres Lésbicas e Bissexuais}

A conquista de um espaço político e social exclusivamente voltado para mulheres ${ }^{2}$ lésbicas e bissexuais começou a aparecer na esfera pública em meio à redemocratização do país.

$\overline{2}$ Neste texto, o termo mulheres é utilizado fazendo referência às mulheres cisgêneras. 
Até então, as pautas discutidas por essas mulheres se misturavam às questões do movimento feminista e homossexual ${ }^{3}$ marcadas pelo caráter secundário que suas demandas eram colocadas. Rememorar alguns pontos da criação desse movimento, bem como as demandas que foram sustentando essa organização, ajuda-nos a refletir sobre as políticas e práticas em torno do cuidado em saúde voltado para mulheres lésbicas e bissexuais.

Para começar a remontar a história do movimento dessas mulheres, voltamos à década de 1970, quando o movimento homossexual passou a ser entendido enquanto movimento social na arena política (Carrara, 2010; Facchini, 2003). Apesar de haver registro de associações homossexuais anteriores, os encontros, a partir de então, começaram a se organizar em torno de uma militância e, assim, ao final da década de 1970, tivemos o surgimento do Grupo Somos (Facchini, 2003).

Nesse momento, ficou marcada a pouca representatividade lésbica, como relata Marisa Fernandes (2018), ao registrar que, em uma das reuniões do grupo, havia dez lésbicas e oitenta gays. Com a centralidade do Movimento Homossexual Brasileiro $(\mathrm{MHB})^{4}$ nas demandas dos homens gays e a reemergência do movimento feminista (Carrara, 2010), as mulheres do MHB criaram um grupo dissidente, chamado Grupo Lésbico Feminista (LF), que em 1981 foi substituído pelo Grupo Ação Lésbica Feminista (Galf).

A aproximação com o movimento feminista foi vista com descontentamento por algumas militantes do movimento lésbico, afirmando haver uma despolitização das questões lésbicas (Martinho, 2006). No entanto foi por essa via que pautas defendidas pelo movimento lésbico alcançaram espaço no cenário político brasileiro.

A luta, no âmbito da conquista de direitos, teve como foco demandas referentes à saúde das mulheres lésbicas e bissexuais, tema do presente artigo. A disputa por direitos reprodutivos e sexuais, em diálogo com as pautas do movimento feminista, e as questões em torno da transmissão de Infecções Sexualmente Transmissíveis (ISTs) no sexo entre mulheres nortearam as primeiras conquistas do movimento.

A partir de 1991, com a criação da Rede Nacional Feminista de Saúde (RFS), uma série de questões relacionadas aos direitos sexuais e reprodutivos das mulheres passaram a ser articuladas em âmbito nacional, possibilitando a discussão de temas antes negligenciados, como o reconhecimento de violência sexual, racial e doméstica como violação de direitos humanos (Rede Feminista de Saúde, 2015).

A integração de uma rede de organizações governamentais, não governamentais, ativistas e pesquisadoras feministas proporcionou à RFS forte presença na construção das políticas públicas brasileiras (Rede Feminista de Saúde, 2015). Dos vários dossiês publicados por elas, o de 2006 foi especificamente voltado para mulheres lésbicas e bissexuais e apontou para a invisibilidade desse grupo na área da saúde (Facchini \& Barbosa, 2006). O dossiê discute uma série de especificidades que permeiam o cuidado em saúde de mulheres lésbicas e bissexuais.

Pautas há tempos levantadas por ativistas do movimento lésbico foram amplamente discutidas no dossiê a partir da apresentação de pesquisas acadêmicas, ainda que fundadas

\footnotetext{
3 Hoje denominado Movimento LGBT+.

${ }^{4}$ As referências utilizadas neste texto, que fazem menção ao surgimento do Movimento Homossexual Brasileiro, estão centradas no eixo dos estados de São Paulo e Rio de Janeiro, apresentando uma visão local e parcial de um movimento mais amplo.
} 
majoritariamente em produções internacionais. Temas como o despreparo médico para atender mulheres lésbicas e bissexuais ou a falsa crença de que o sexo entre mulheres não transmite ISTs e que, portanto, as deixaria isentas de se protegerem durante suas relações sexuais (Pompeu, 2001) foram esmiuçados no dossiê e demonstraram a escassez de produção na arena acadêmica brasileira.

Ainda que tenha havido avanços no campo, textos recentes (Fernandes, Soler, \& Leite, 2018; Soares, Peres, \& Dias, 2017; Silva, 2015) ainda fazem referência à ineficiência dos serviços de saúde oferecidos a essas mulheres. Os efeitos dessa ineficiência são inúmeros, como: as mulheres continuam sem acesso a informações acerca das especificidades de proteção no sexo lésbico e, por consequência, de como podem cuidar da sua saúde de forma efetiva; muitas delas relatam experiências ruins ao procurarem um profissional de saúde; devido à desinformação dos profissionais de saúde acerca da saúde da mulher lésbica e bissexual, elas acabam não frequentando esses espaços; e efeitos na saúde mental das muIheres, em casos decorrentes de violências já vividas, relacionadas à sexualidade (Fernandes et al., 2018).

Pensando nos discursos e realidades produzidos por e nesse caminho da saúde de muIheres lésbicas e bissexuais, a seguir revisitaremos as políticas públicas brasileiras ${ }^{5}$ que fazem menção ou são voltadas a essas mulheres, em diálogo com o campo acadêmico e ativista, para refletir sobre os efeitos de tais políticas na atenção à saúde de mulheres lésbicas e bissexuais.

\section{As Políticas Públicas de Saúde}

Os quinze documentos apresentados e analisados nesta seção, listados nas tabelas 1 e 2, foram selecionados a partir do resgate histórico das demandas configuradas pelo ativismo lésbico, ou seja, buscamos as políticas que se estruturaram em decorrência das articulações do movimento lésbico tanto com o movimento feminista quanto com o movimento LGBT+ para dar visibilidade às pautas que essas mulheres identificavam como prioridade para a sua saúde, de modo que os seguintes textos foram incluídos no escopo da pesquisa: "Assistência Integral à Saúde da Mulher: Bases da Ação Programática" (1984); "Política Nacional de Atenção Integral à Saúde da Mulher - Princípios e Diretrizes" (2004); "Plano Nacional de Políticas para as Mulheres" (2005); "Chegou a Hora de Cuidar da Saúde" (2006); "Plano Integrado de Enfrentamento da Feminização da Epidemia da Aids e outras DST" (2007); "II Plano Nacional de Políticas para as Mulheres" (2008b); "Plano Integrado de Enfrentamento da Feminização da Aids e Outas DST - Versão Revisada" (2009); "Política Nacional de Saúde Integral de Lésbicas, Gays, Bissexuais, Travestis e Transexuais" (2012); "Atenção Integral à Saúde de Mulheres Lésbicas e Bissexuais" (2014).

\footnotetext{
${ }_{5}^{5}$ Algumas políticas apresentadas aqui, como o Plano Nacional de Políticas para Mulheres, não estão mais em vigência. No entanto sua análise é importante por representar construções e movimentações históricas, que estão em constante mudança.
} 
Tabela 1

Documentos da política de saúde em articulação com questões feministas e LGBT+

\begin{tabular}{|l|c|l|}
\hline \multicolumn{1}{|c|}{ Documento } & Ano & \multicolumn{1}{|c|}{ Finalidade } \\
\hline $\begin{array}{l}\text { Assistência Integral à Saúde da Mulher: } \\
\text { Bases da Ação Programática }\end{array}$ & 1984 & $\begin{array}{l}\text { Primeiro documento que versa sobre a saúde } \\
\text { da mulher, indo além da lógica materno-infantil } \\
\text { que operava até então. }\end{array}$ \\
\hline $\begin{array}{l}\text { Política Nacional de Atenção Integral à } \\
\text { Saúde da Mulher - Princípios e Diretrizes }\end{array}$ & 2004 & $\begin{array}{l}\text { Atualização da Política de Saúde, com uma seção } \\
\text { direcionada às mulheres lésbicas e bissexuais. }\end{array}$ \\
\hline $\begin{array}{l}\text { Plano Nacional de Políticas para as } \\
\text { Mulheres (PNPM I) }\end{array}$ & 2005 & $\begin{array}{l}\text { Criado pela Secretaria Especial de Políticas para } \\
\text { as Mulheres com o intuito de promover a igual- } \\
\text { dade entre homens e mulheres. }\end{array}$ \\
\hline $\begin{array}{l}\text { Chegou a Hora de Cuidar da Saúde } \\
\text { Plano Integrado de Enfrentamento da } \\
\text { Feminização da Epidemia da Aids e ou- } \\
\text { tras DST }\end{array}$ & 2007 & $\begin{array}{l}\text { Fruto da Política Nacional de DST/Aids, a cartilha } \\
\text { fala de alguns aspectos sobre a saúde de mulhe- } \\
\text { res lésbicas e bissexuais. }\end{array}$ \\
\hline $\begin{array}{l}\text { II Plano Nacional de Políticas para as } \\
\text { Mulheres (PNPM II) }\end{array}$ & 2008 & $\begin{array}{l}\text { Documento norteador da implementação de } \\
\text { açes voltadas para mulheres, relacionadas ao } \\
\text { diagnóstico e tratamento de DSTs e aids. }\end{array}$ \\
\hline $\begin{array}{l}\text { Plano Integrado de Enfrentamento da } \\
\text { Feminização da Aids e outras DST - ver- } \\
\text { são revisada }\end{array}$ & 2009 & $\begin{array}{l}\text { Atualização do PNPM I, que traz ações específi- } \\
\text { cas voltadas para mulheres lésbicas. }\end{array}$ \\
\hline $\begin{array}{l}\text { Política Nacional de Saúde Integral de } \\
\text { Lésbicas, Gays, Bissexuais, Travestis e } \\
\text { Transexuais }\end{array}$ & 2012 & $\begin{array}{l}\text { Versa atualizada, agora com uma seção voltada } \\
\text { para mulheres lésbicas e bissexuais. }\end{array}$ \\
\hline $\begin{array}{l}\text { Atenção Integral à Saúde de Mulheres } \\
\text { Lésbicas e Bissexuais }\end{array}$ & 2014 & $\begin{array}{l}\text { Construído com o intuito de visibilizar as ques- } \\
\text { tões de saúde LGBT+. O documento também } \\
\text { aponta para a invisibilidade histórica das mulhe- } \\
\text { res lésbicas no movimento LGBT+. }\end{array}$ \\
\hline $\begin{array}{l}\text { Documento específico voltado para pensar um } \\
\text { cuidado em saúde específico para mulheres lés- } \\
\text { bicas e bissexuais. }\end{array}$ \\
\hline
\end{tabular}

Os outros seis documentos adicionados ao recorte histórico que apresentamos aqui dizem respeito à estruturação do modelo de saúde pública e também apareceram como cruciais para a construção das políticas de saúde para as mulheres lésbicas e bissexuais, sendo quatro deles: Constituição da República Federativa do Brasil (1988); 12a Conferência Nacional de Saúde (2003); 13a Conferência Nacional de Saúde (2008a); e a Lei n. 8.080 (1990). Ainda, a Resolução n. 614 (2019) e o Decreto n. 9.795 (2019) foram incluídos nas análises, uma vez que representam as mudanças que estão por vir na estrutura regimental do Ministério da Saúde sob a nova gestão governamental do Brasil, as quais incidem diretamente nas políticas e práticas de saúde voltadas para mulheres lésbicas e bissexuais. 
Tabela 2

Documentos que estruturam a política de saúde

\begin{tabular}{|c|c|c|}
\hline Documento & Ano & Finalidade \\
\hline $\begin{array}{l}\text { Constituição da República } \\
\text { Federativa do Brasil }\end{array}$ & 1988 & $\begin{array}{l}\text { Instituiu o Sistema Único de Saúde (SUS), colocando a saú- } \\
\text { de como um direito social de competência dos poderes } \\
\text { públicos. }\end{array}$ \\
\hline Lei n. 8.080 & 1990 & $\begin{array}{l}\text { Lei que regula as ações e os serviços de saúde em todo o } \\
\text { território nacional. }\end{array}$ \\
\hline $\begin{array}{l}\text { 12a Conferência Nacional de } \\
\text { Saúde }\end{array}$ & 2003 & $\begin{array}{l}\text { Inclusão da orientação sexual e identidade de gênero } \\
\text { como determinantes sociais de saúde. }\end{array}$ \\
\hline $\begin{array}{l}\text { 13a Conferência Nacional de } \\
\text { Saúde }\end{array}$ & 2008 & $\begin{array}{l}\text { Inclusão da orientação sexual e identidade de gênero } \\
\text { como determinantes sociais de saúde. }\end{array}$ \\
\hline Resolução n. 614 & 2019 & $\begin{array}{l}\text { O Conselho Nacional de Saúde aprova diretrizes referen- } \\
\text { tes à Programação Anual de Saúde e o Projeto de Lei de } \\
\text { Diretrizes Orçamentárias da União para } 2020 \text {. }\end{array}$ \\
\hline Decreto n. 9.795 & 2019 & $\begin{array}{l}\text { Alteração da estrutura regimental do Ministério da Saúde, } \\
\text { fundindo o Departamento de ISTs, Aids e Hepatites Virais } \\
\text { ao de Doenças e Condições Crônicas. }\end{array}$ \\
\hline
\end{tabular}

Os documentos selecionados foram lidos e repensados a partir de uma epistemologia feminista, política e eticamente atenta às "oportunidades para propor melhores problemas do que aqueles dos quais partimos" (Harding, 1993, p. 12), em outras palavras, Harding (1993) propõe uma produção de conhecimento que desestabilize categorias analíticas já postas, possibilitando acessar aquilo que ainda não foi visibilizado. Em diálogo com o ativismo lésbico, que teve e tem como pauta a visibilidade de suas demandas na arena política, acadêmica e social, buscamos compreender quais discursos foram produzidos e reiterados pelas políticas de saúde mencionadas nos parágrafos anteriores e que possibilidades de cuidado em saúde foram visibilizadas em detrimento de outras. Assim, apresentaremos este histórico entremeado às reflexões teóricas produzidas por nossas análises.

A saúde no Brasil começou a ser delineada como a conhecemos hoje em 1988, a partir da Constituição Federal (Brasil, 1988) e, junto dela, do Sistema Único de Saúde (SUS) (Brasil, 1990) (Rede Feminista de Saúde, 2008) e da Lei n. 8.080, que regula as ações e os serviços de saúde em todo o território nacional. Embora seja importante apontar que, na história da saúde pública brasileira, foram fundamentais, antes de 1988, alguns marcadores que colaboraram para a constituição de um modelo público de assistência e cuidado à saúde (Bertolli Filho, 2001).

Desde então, entendemos a saúde como um direito social, de acesso a todos, assegurada como competência dos poderes públicos (Brasil, 1988). Paralelamente, dois fatores também tiveram forte influência na forma como as políticas no Brasil foram sendo construídas: o viés materno-infantil das políticas de atenção à saúde das mulheres no cenário internacional (Rede Feminista de Saúde, 2008) e a resposta brasileira à epidemia da aids (Calais \& Perucchi, 2017).

As políticas públicas brasileiras se alicerçaram em duas pautas estreitamente relacionadas à invisibilidade lésbica. Se, de um lado, as lésbicas eram cobradas por serem mulheres, engravidarem e usarem seus corpos como o destino biológico prediz, de outro, não eram 
consideradas mulheres, como afirma Wittig (2012), por se distanciarem de uma cultura heterossexual; e, como a gravidez só seria possível nessa lógica, a maternidade não existiria como possibilidade para essas mulheres. A ideia do sexo lésbico como preliminar do sexo heterossexual, o sexo de verdade, isentava-as de qualquer risco relacionado à epidemia de aids. Assim como o sexo lésbico não existia, a lésbica, como sujeita abjeta (Butler, 1999), não existia no campo inteligível da norma.

Nesse âmbito de disputa discursivo, em que determinadas vidas são vistas ou não pelas políticas produzidas pelo estado, o movimento feminista lutava por avanços relacionados aos direitos sexuais e reprodutivos das mulheres. Até meados de 1980, a visão materno-infantil predominava no país (Rede Feminista de Saúde, 2008), materializando-se na construção dos primeiros programas voltados à saúde das mulheres, elaborados nas décadas de 1930, 1950 e 1970, que traduziam uma visão restrita sobre a mulher, baseada em sua especificidade biológica e no seu papel social de mãe e doméstica (Brasil, 2004). Duas lógicas operavam até então, havia uma postura de incentivo à natalidade e uma legislação que preconizava a maternidade, em detrimento da autonomia das mulheres sobre seus corpos (Rede Feminista de Saúde, 2008).

Em resposta ao cenário econômico mundial, as políticas de controle de natalidade em países em desenvolvimento começaram a operar; dessa forma, modificou-se o objetivo final do aparelho estatal, mas a via de controle permaneceu a mesma: os corpos das mulheres. 0 movimento feminista se posicionou contrário a essas práticas autoritárias e, em consonância com a reforma sanitária da década de 1980, surgiu o Programa de Assistência Integral à Saúde da Mulher, o Paism (Rede Feminista de Saúde, 2008). O documento procurou romper com a concepção materno-infantil e a lógica de controle à autonomia delas, mas ainda propôs resoluções majoritariamente voltadas aos métodos contraceptivos e gravidez (Brasil, 1984).

Uma das fortes críticas ao feminismo, retomando o conceito de corpos abjetos de Butler (1999), era de visibilizar e legitimar demandas de um grupo específico de mulheres, como se fossem uma unidade. No entanto outros corpos ficavam, e ficam, de fora dessas pautas e avanços, como as mulheres lésbicas e as mulheres negras. Anzaldúa (2005), em 1987, já apontava para o lugar fronteiriço de uma mulher que é ao mesmo tempo lésbica e não branca, colocada nesse limbo em que não existe em um lugar nem em outro, dentro dessa lógica binária. Sueli Carneiro (2003) discutiu a necessidade da incorporação das questões raciais às discussões e demandas organizadas pelo movimento feminista. Especificamente em relação à saúde, a autora discorre sobre a invisibilidade das condições de saúde das mulheres negras brasileiras, a conversa inexistente sobre doenças étnicas/raciais e a esterilização maciça da população negra.

Na década de 1990, com a Conferência Internacional de População e Desenvolvimento (Cipd) no Cairo, em 1994, e a Conferência Mundial sobre Mulheres em Beijing, em 1995, a saúde reprodutiva e a saúde sexual foram colocadas e legitimadas como um direito às cidadãs e como um dever do Estado (Facchini, 2008; Rede de Saúde Feminista, 2008). O caminho por uma afirmação dos direitos reprodutivos e sexuais aconteceu tanto no âmbito internacional como nacional. No Brasil, paralelamente à luta pela liberdade e autonomia dos corpos das mulheres no campo da saúde reprodutiva e sexual, ocorreu, segundo Calazans, Pinheiro e Ayres (2018), a consolidação do Programa Nacional DST/Aids (PN-DST/Aids). 
Em meio a esse cenário, o Movimento Lésbico estava com caminhos abertos para pensar articulações na esfera governamental referentes aos direitos dessas mulheres, especificamente no campo da saúde. Em 1996, com a participação de 100 lésbicas, aconteceu o primeiro Seminário Nacional de Lésbicas (VI Senale, 2006), justamente com o suporte do Ministério da Saúde via o PN-DST/Aids, e parece ter havido uma mescla da busca por visibilidade política das lésbicas com a procura por visibilidade diante das DSTs, colocando a demanda por saúde e direitos sexuais como prioridade nas reivindicações do movimento (Almeida, 2009).

A parceria do movimento lésbico com o PN-DST/Aids, além do Senale, propiciou a elaboração do Grupo Matricial, uma instância de diálogo permanente entre o Ministério da Saúde e o movimento lésbico. Apesar da sua importância política na década de 1990, as demandas de saúde produzidas por ele não obtiveram as respostas estatais esperadas e a aproximação do movimento com o Ministério da Saúde não aconteceu sem atritos entre algumas militantes, que não viam sentido na associação das lésbicas à discussão da aids (Almeida, 2009).

Os Senale que aconteceram nos anos seguintes, em 1997, 1998 e 2001, assim como o primeiro, pautaram temas referentes à saúde das mulheres lésbicas (Facchini \& Barbosa, 2006; Fernandes et al., 2018). As temáticas centrais dos quatro primeiros Senale, em ordem cronológica, foram: Saúde, Visibilidade e Organização; Saúde e Cidadania; Saúde e Visibilidade; e Cidadania, Visibilidade, Saúde e Organização (VI Senale, 2006). A aposta de visibilidade pela via da saúde se torna evidente com essa sequência de encontros sobre o mesmo tema, que continuaram acontecendo nos anos seguintes, em outros eventos promovidos pelo movimento lésbico. Em 2004, com a Política Nacional de Atenção Integral à Saúde da Mulher (Pnaism), houve a construção de uma seção direcionada às lésbicas, denotando um avanço em relação ao Paism de 1984, que não fazia menção alguma às questões do movimento lésbico. Assim, foram citados pontos importantes discutidos no último Senale, em 2003, e na agenda política dessas mulheres, como: os atendimentos ginecológicos heteronormativos oferecidos às mulheres, a ideia de que mulheres lésbicas não estão em risco em relação ao câncer de colo de útero, a vulnerabilidade em relação às DSTs pelas mulheres lésbicas profissionais do sexo, a violência intrafamiliar à qual adolescentes lésbicas podem estar expostas e o acesso à inseminação assistida na rede do SUS (Brasil, 2004).

A publicação da política nacional com algumas das pautas do movimento lésbico significava um avanço na conquista da visibilidade política, no entanto permaneciam como desafio os caminhos viáveis para a implementação de mudanças a partir dos problemas expostos, já que o documento não trazia propostas sobre isso em seu Plano de Ação. As informações expostas no texto da política assinalavam tópicos importantes defendidos pelo movimento e que geravam uma série de complicadores para o cuidado efetivo dessa população, todavia algumas críticas podem ser feitas. O texto da Pnaism discorre sobre a vulnerabilidade em relação às ISTs, mas somente para as mulheres lésbicas profissionais do sexo. Em sequência, a temática da violência aparece, porém também restrita a um público específico, as adolescentes.

No campo acadêmico, a temática da saúde das mulheres lésbicas e bissexuais ganha visibilidade no lançamento do dossiê, em 2006, por Facchini e Barbosa (2006), em que as autoras apresentam uma revisão da literatura, discutindo as especificidades no cuidado voltado às mulheres lésbicas e bissexuais, as violências sofridas, a incipiência do serviço de saúde 
oferecido a elas e consequente evasão nos espaços de cuidado institucional. As autoras o fazem com produções acadêmicas internacionais, demarcando a escassez na produção brasileira sobre o tema.

Em textos mais recentes, as questões apresentadas no dossiê ainda se fazem presentes. Segundo Soares, Peres e Dias (2017), os dados epidemiológicos relacionados à temática são escassos e as produções acadêmicas existentes denunciam a evasão nos serviços de saúde (Soares, Peres, \& Dias, 2017; Silva, 2015). A vulnerabilidade dos corpos lésbicos em relação aos cânceres de colo de útero e de mama (Watermann \& Voss, 2015; Cochran \& Mays, 2012) é majoritariamente discutida por autores internacionais, assim como o despreparo profissional para atendê-las (Curmi, Peters, \& Salamonson, 2014), reiterando mais uma vez a incipiência da produção no que se refere à saúde de mulheres lésbicas e bissexuais.

Ainda em 2006, a convite do PN-DST/Aids, foi lançada a cartilha "Chegou a Hora de Cuidar da Saúde". Uma publicação curta, que perpassa alguns temas relacionados à saúde das muIheres lésbicas e bissexuais, como o direito de viver a homossexualidade, a descoberta da sexualidade na adolescência, o racismo. A cartilha fala da saúde de modo integral, ao trazer a alimentação, exercícios físicos e o uso de drogas em uma perspectiva de redução de danos, como caminhos de cuidado possíveis, e explora a saúde sexual e reprodutiva, quando fala das visitas periódicas a ginecologistas, da prevenção de cânceres de mama e colo do útero, da gravidez e das DSTs (Brasil, 2006).

A visibilidade das lésbicas na arena política, como exposto no histórico até aqui, está em constante disputa. Há momentos de oscilação na priorização e legitimação das demandas nos documentos publicados pelo governo federal, a exemplo do Plano Nacional de Políticas para as Mulheres (PNPM), tanto o I, lançado em 2005 logo após a publicação do Pnaism, quanto o II, em 2008. Os PNPM I e II se fundamentam em pontos como a igualdade, o respeito à diversidade e a autonomia das mulheres (Brasil, 2005; Brasil, 2008b). Segundo Calderaro (2011), é possível observar um avanço em relação aos dois planos, uma vez que o segundo, de 2008, traz ações específicas voltadas para as mulheres lésbicas, reconhecendo a orientação e as práticas sexuais como determinantes no cuidado em saúde.

O mesmo aconteceu com o Plano Integrado de Enfrentamento da Feminização da Epidemia de Aids e outras DST de 2007. O documento, pautado na promoção da saúde sexual e saúde reprodutiva, buscava nortear a implementação de ações relacionadas ao diagnóstico e tratamento de DSTs e da aids especificamente para mulheres. No texto, a vulnerabilidade de mulheres lésbicas e bissexuais aparece, no entanto não são descritas possibilidades de ação voltadas a ela (Brasil, 2007). Em 2009, a partir da discussão com diversos grupos de mulheres, foi publicada uma versão revisada do plano, com agendas afirmativas pautadas nos diversos contextos de vulnerabilidades, como as mulheres lésbicas e bissexuais, as transexuais, as prostitutas, entre outras (Brasil, 2009).

Mais adiante, o Ministério da Saúde lançou a Política Nacional de Saúde Integral de Lésbicas, Gays, Bissexuais, Travestis e Transexuais (2012), em uma tentativa de visibilizar questões de saúde LGBT+, buscando reconhecer os efeitos da discriminação e da exclusão nesse âmbito. Na descrição, a política fala sobre a trajetória de invisibilidade das mulheres lésbicas tanto no Grupo Somos como nas ações de prevenção à aids, caminho alterado ao se aproximarem do movimento feminista, propiciando a emergência desse debate no âmbito da conquista de direitos (Brasil, 2012). Um dos marcos da política de saúde LGBT+, discutidos 
nas Conferências Nacionais de Saúde que ocorreram em 2003 e 2007 (Brasil, 2003; Brasil, 2008a), foi a inclusão da orientação sexual e identidade de gênero como determinantes sociais de saúde.

Dos temas específicos relacionados à saúde da mulher lésbica e bissexual descritos na política, aparecem as questões já citadas neste texto, relacionadas à prevenção de cânceres ginecológicos, ao acesso a um tratamento qualificado, bem como ao cuidado a questões relacionadas à saúde mental (Brasil, 2012). Mas permanece a demanda do movimento de mulheres lésbicas e bissexuais, presente desde as primeiras organizações do movimento homossexual: as pautas da agenda política de mulheres lésbicas e bissexuais seguem diluídas e invisibilizadas em meio às do movimento como um todo.

Em resposta a essa lacuna, o livreto de Atenção Integral à Saúde de Mulheres Lésbicas e Bissexuais (2014) discute os determinantes de vulnerabilidades na assistência à saúde e repensa elementos para a proposição de um cuidado que garanta a integralidade na atenção à saúde dessas mulheres. Alguns dados e indicadores de saúde apresentados exploram as questões há muito pautadas pelo movimento, como o acolhimento insuficiente nos atendimentos oferecidos, a saúde da mulher focada na reprodução, a importância da educação e formação de profissionais e a discussão de como conversar sobre a orientação sexual de um modo acolhedor, pensando que esse pode ser um tema tabu (Brasil, 2014).

Apresentamos até aqui o resgate histórico das políticas de cuidado em saúde voltadas para as mulheres lésbicas e bissexuais, já apontando algumas normatividades e tensões na forma como tais políticas têm sido organizadas e implementadas. A seguir, dissertaremos sobre os resultados de nossas análises, retomando alguns pontos já discutidos e explorando outras inquietações.

Um dos temas discutidos no livreto de Atenção Integral à Saúde de Mulheres Lésbicas e Bissexuais (2014), ainda invisibilizado na trajetória do movimento lésbico, está relacionado às mulheres bissexuais. As reflexões apresentadas fazem menção à falta de espaço para a identidade bissexual dentro do movimento LGBT+, que se estende para o apagamento nas pesquisas sobre saúde voltadas para essa população. Para além da invisibilidade, o documento aborda o estigma em torno da sexualidade bi, muitas vezes colocada como "vetores" de DSTs (Brasil, 2014). Em 2016, na oitava edição do Senale, vinte anos após o primeiro encontro, o termo bi foi adicionado à sigla Senale, que a partir de então se nomeou Senalesbi, dando protagonismo às questões específicas das mulheres bissexuais (Fernandes, 2018).

As produções acadêmicas sobre a temática da bissexualidade corroboram o exposto no livreto. Segundo Alberto (2018) e Pamplona e Dinis (2013), os discursos sobre bissexualidade comumente giram em torno de um privilégio, por terem acesso tanto a homens quanto muIheres. Em contrapartida, Alberto (2018) discorre sobre as ideias estereotipadas da bissexualidade como identidade transitória ou indecisão e a suposta promiscuidade dessas pessoas, discursos que minimizam essa identidade, colocando-a num lugar abjeto.

A invisibilidade bissexual dentro do movimento lésbico, das produções acadêmicas e na construção das políticas públicas chama atenção para a reprodução da heteronormatividade (Berlant \& Warner, 1998) na busca por direitos na arena política. Como norma estruturante da nossa sociedade, a heteronormatividade é reproduzida nos diversos contextos em que nos organizamos como grupo, e, por mais que algumas identidades e performatividades (Butler, 1999) sejam periféricas nessa norma, elas acabam por reiterar essa suposta 
coerência heteronormativa, em que esperamos que um determinado sexo corresponda a uma determinada orientação sexual, que, por consequência, deve manter determinadas práticas sexuais, todas em conformidade com o gênero que se performa.

Em diálogo com essa lógica que nos regula, outro ponto de tensionamento surge na tentativa de visibilizar as demandas do movimento lésbico: a criação do termo epidemiológico MSM para se referir a mulheres que fazem sexo com mulheres, mas que não se identificam como lésbicas ou bissexuais. Como uma tentativa de ampliação das demandas de saúde lésbicas, a proposição do termo epidemiológico $\mathrm{MSM}^{6}$ (mulheres que fazem sexo com mulheres), importado de pesquisas no cenário internacional, pretendia ampliar o alcance numérico das políticas de saúde, no entanto ela não foi bem recebida pelo movimento (Almeida \& Heilborn, 2008). Segundo os autores, há pouca tolerância entre as ativistas lésbicas brasileiras com mulheres que mantêm relações sexuais com outras mulheres, mas não se autorreferem como lésbicas. Soares, Peres e Dias (2017) argumentam que o termo reduz um universo plural do que é ser lésbica, composto por afetividades, saúde, cultura, a um comportamento sexual.

Indo além nas reflexões acerca das normatividades produzidas nas políticas públicas brasileiras, Meinerz (2011) discute sobre a lésbicas que não performam a feminilidade esperada à categoria mulher. A autora reflete sobre como uma expressão de gênero localizada mais próxima do masculino é vista com maus olhos, exceto quando são performances andróginas, que se associam ao rompimento da norma de forma transgressora. As caminhoneiras, dykes ou bofinhos são colocadas no escopo da masculinidade grosseira, desleixada e despreocupada com o estético (Meinerz, 2011). As reflexões acerca desse estigma permearam também o movimento lésbico. Almeida (2005) descreve as ponderações das ativistas, quando elas afirmam que as lésbicas vão além do modelo dual lady/dyke, em que uma se aproximará de performances mais femininas e outra mais masculinas, reproduzindo o modelo binário e heteronomartivo descrito por Butler (1999). Meineirz (2011) reflete sobre como essa foi uma estratégia do movimento para se afastar de estereótipos que desencadeiam preconceitos, além de ser um posicionamento crítico a comportamentos machistas que reproduzem hierarquias de gênero.

A questão racial também perpassa os tensionamentos do movimento lésbico e bissexual, que em resposta criou o I Seminário Nacional de Lésbicas Negras: Afirmando Identidades, em 2006 (Fernandes, 2018). O encontro, segundo a autora, propiciou diálogo entre orientação sexual, identidade de gênero e o debate antirracista no país, uma agenda necessária para discutir questões pertinentes à mulher negra dentro do feminismo, como já apontado por Carneiro (2003), e do movimento lésbico e bissexual.

Para além das questões heteronormativas reproduzidas no percurso das políticas públicas construídas para afirmar os direitos das lésbicas no âmbito da saúde, as demandas das mulheres lésbicas e bissexuais, pontuadas desde os primeiros encontros dessas mulheres organizadas enquanto movimento social, relatando o despreparo profissional e a consequente evasão das mulheres nos serviços de saúde, mantêm-se como questão até hoje. As ações propostas nas políticas públicas direcionadas à melhora na formação de profissionais de saúde

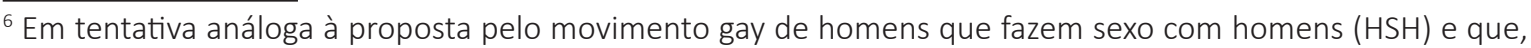
mesmo que apareça mais frequentemente, foi também alvo de uma série de questionamentos.
} 
não surtiram efeito. Rodrigues (2018), em revisão bibliográfica sobre a temática, discorre sobre as idas à ginecologista com frequência irregular, os receios em falar da orientação sexual em consultas, a falta de reconhecimento das práticas sexuais entre mulheres, além dos encaminhamentos equivocados nas consultas em relação a exames preventivos, por exemplo.

Os documentos produzidos pelo governo federal, em diálogo com o movimento social lésbico e bissexual, e os textos acadêmicos apresentados até aqui possibilitaram remontar o histórico das políticas públicas de saúde voltados para esse público, bem como os efeitos relacionados ao cuidado oferecido a elas em espaços institucionais de saúde. A partir do exposto, conseguimos acessar uma série de tensões e demandas encontradas nas políticas de saúde para mulheres lésbicas e bissexuais, produzidas nos encontros e em disputas com as pautas defendidas pelo movimento feminista, negro e LGBT+.

Apesar das demandas do movimento lésbico e bissexual aparecerem nos textos dos vários documentos públicos apresentados aqui, é possível questionar o quanto da precariedade e vulnerabilidade (Butler, 2011) dessas mulheres consegue alcançar reconhecimento, por exemplo, em meio aos profissionais de saúde. O ponto aqui é questionar o porquê da distância entre os textos contidos nas políticas, em que parece haver um avanço no cuidado oferecido às mulheres lésbicas e bissexuais, e o cotidiano das que procuram de alguma forma cuidar da própria saúde, em que comumente acessam desinformação e discriminação por parte dos profissionais.

O conceito de precariedade de Butler (2011) ajuda a pensar no processo discursivo e social em que vamos colocando determinadas identidades e performatividades no campo do humano e outras no do não humano. Conforme o enquadramento, certos sujeitos e populações são lançados à condição precária, "condição politicamente induzida na qual certas populações sofrem com redes sociais e econômicas de apoio deficientes e ficam expostas de forma diferenciada às violações, à violência e à morte" (Butler, 2015, p. 46). Ou seja, algumas populações são entendidas como sujeitos de direito, legítimos para reivindicarem condições justas no acesso à saúde, e outras são compreendidas como abjetos e suas demandas não são sequer enxergadas pelo sistema de saúde.

É possível analisar que somente na precarização das vidas de mulheres lésbicas e bissexuais é que produzimos uma política de cuidado. Política que está posta nos documentos, mas que nem sequer chega como informação para essas mulheres, considerando-se a veiculação de informação como uma ferramenta fundamental na manutenção de hierarquias já postas. Além disso, tamanha a abjeção desses corpos, que profissionais de saúde não compreendem essa forma de vivenciar a sexualidade como legítima para acessar algum tipo de cuidado.

\section{Considerações}

Objetivando revisar as políticas de saúde voltadas para mulheres lésbicas e bissexuais, este texto buscou compreender, a partir de uma epistemologia feminista, as condições de possibilidade para a emergência dessas políticas e as tensões que colocam diferentes sujeitos e bandeiras em disputa. Esta breve sistematização permite algumas reflexões sobre complexos movimentos políticos das últimas décadas.

Alicerçados pelo arcabouço teórico produzido por teóricas feministas ao longo dos anos, foi possível revisitar criticamente a construção dessas políticas públicas de saúde entremeadas 
aos caminhos do ativismo lésbico brasileiro. Assim, fomos apontando para uma série de tensões que se construíram nesse percurso, como a invisibilidade de mulheres negras e lésbicas dentro do próprio movimento feminista ou o apagamento da bissexualidade no movimento lésbico. O silenciamento de determinados corpos e performatividades não aconteceu por acaso, mas sim operado por uma lógica heteronormativa, que visibilizou algumas vidas em detrimento de outras.

Com embates políticos que levam em conta enquadramentos de gênero, sexualidade, raça, entre outros, o movimento de mulheres lésbicas e bissexuais reivindica espaço em políticas de saúde direcionadas para mulheres - historicamente centradas na saúde reprodutiva - e em políticas voltadas para a população LGBT+ - marcadas inicialmente pelo controle à epidemia da aids. A partir desses tensionamentos, algumas bandeiras específicas passam a ganhar espaço em documentos e cartilhas.

As políticas públicas de saúde, portanto, ainda se mostram insuficientes quando pensamos nas problemáticas de sua construção e nos desafios de sua implementação. Ainda assim, estávamos em um momento político de abertura para o diálogo com movimentos sociais, mas recentemente temos visto uma transformação nesse campo de debate, como anunciado no início deste texto. Com a extinção das Secretarias de Direitos Humanos e de Políticas para Mulheres, com um corte orçamentário significativo nas questões pertinentes às mulheres (Gonçalves \& Abreu, 2018) e mudança da estrutura do Departamento de ISTs, Aids e Hepatites Virais para Departamento de Doenças e Condições Crônicas e Infecções Sexualmente Transmissíveis (Decreto n. 9.795), percebemos mudanças significativas na forma como o governo tem encarado o cuidado à saúde das mulheres e, especificamente neste artigo, das mulheres lésbicas e bissexuais.

Na Resolução n. 614, de fevereiro de 2019, o Conselho Nacional de Saúde (CNS) afirma a garantia da atenção integral da saúde da mulher e das pessoas LGBT+, no entanto alterações estruturais, como as propostas no Decreto n. 9.795, apontam para uma precarização ainda maior dos direitos das mulheres lésbicas e bissexuais, de modo que, para além de reformular as apostas de cuidado apresentadas nos documentos abordados aqui, as análises precisam ir além das que percorremos até então. Os retrocessos no campo da conquista de direitos sociais têm operado em uma nova gramática que exige de nós um esforço em pensar outras formas de resistência, especialmente quando fazemos referência a identidades e performatividades historicamente negligenciadas e silenciadas.

\section{Financiamento}

O presente trabalho foi realizado com apoio da Coordenação de Aperfeiçoamento de Pessoal de Nível Superior- Brasil (CAPES), Código de Financiamento 001.

\section{Referências}

Alberto, J. A. (2018). Bissexualidade(s): Crenças e opiniões (Dissertação de mestrado em Psicologia, Escola de Ciências Sociais, Departamento de Psicologia, Universidade de Évora, Évora).

Almeida, G. (2005). Da invisibilidade à vulnerabilidade: Percursos do "corpo lésbico" na cena brasileira face à possibilidade da infecção por DST e AIDS (Tese de doutorado em 
Saúde Coletiva, Instituto de Medicina Social, Universidade Estadual do Rio de Janeiro, Rio de Janeiro).

Almeida, G. (2009). Argumentos em torno da possibilidade de infecção por DST e AIDS entre mulheres que se autodefinem como lésbicas. Physis: Revista de Saúde Coletiva, 19(2), 301-331.

Almeida, G., \& Heilborn, M. L. (2008). Não somos mulheres gays: Identidade lésbica na visão de ativistas brasileiras. Gênero, 9(1/2), 225-249.

Anzaldúa, G. (2005). La conciencia de la mestiza: Rumo a uma nova consciência. Revista Estudos Feministas, 13(3),704-719.

Berlant, L., \& Warner, M. (1998). Sex in Public. Critical Inquiry, 24(2), 547-566.

Bertolli Filho, C. (2001). História da Saúde Pública no Brasil. São Paulo: Editora Ática.

Brasil. (1984). Assistência integral à saúde da mulher: Bases da ação programática. Brasília: Ministério da Saúde.

Brasil. (1988). Constituição da República Federativa o Brasil. Brasília: Senado Federal.

Brasil. (2003). 12ª Conferência Nacional de Saúde. Brasília: Ministério da Saúde.

Brasil. (2004). Política Nacional de Atenção Integral à Saúde da Mulher - Princípios e Diretrizes. Brasília: Ministério da Saúde.

Brasil (2005). Plano Nacional de Políticas para as Mulheres. Brasília: Secretaria Especial de Políticas para as Mulheres.

Brasil. (2006). Chegou a hora de cuidar da saúde. Brasília: Ministério da Saúde.

Brasil. (2007). Plano Integrado de Enfrentamento da Feminização da Epidemia da Aids e outras DST. Brasília: Ministério da Saúde.

Brasil. (2008a). 13a Conferência Nacional de Saúde. Brasília: Ministério da Saúde.

Brasil. (2008b). II Plano Nacional de Políticas para as Mulheres. Brasília: Secretaria Especial de Políticas para as Mulheres.

Brasil. (2009). Plano Integrado de Enfrentamento da Feminização da Epidemia da Aids e outras DST - Versão Revisada. Brasília: Ministério da Saúde.

Brasil. (2012). Política Nacional de Saúde Integral de Lésbicas, Gays, Bissexuais, Travestis e Transexuais. Brasília: Ministério da Saúde.

Brasil. (2014). Atenção Integral à Saúde de Mulheres Lésbicas e Bissexuais. Brasília: Ministério da Saúde.

Butler, J. (1999). Gender Trouble: Feminism and the subversion of identity. New York and London: Routledge.

Butler, J. (2011). Vida precária. Tradução: Angelo Marcelo Vasco. Contemporânea, 1, 13-33.

Butler, J. (2015). Quadros de guerra: Quando a vida é passível de luto? Tradução: Sérgio T. M. Lamarão e Arnaldo M. da Cunha. Rio de Janeiro: Civilização brasileira.

Carneiro, S. (2003). Enegrecer o feminismo: A situação da mulher negra na América Latina a partir de uma perspectiva de gênero. In: Ashoka Empreendimentos Sociais; Takano Cidadania (Org.). Racismos contemporâneos. Rio de Janeiro: Takano Editora.

Carrara, S. (2010). Políticas e Direitos Sexuais no Brasil Contemporâneo. Revista Bagoas Estudos Gays: Gênero e Sexualidades, 4(5). Disponível em https://periodicos.ufrn.br/bagoas/ article/view/2316 
Calais, L. B., \& Perucchi, J. (2017). Políticas Públicas de Prevenção ao HIV/AIDS: uma aproximação entre França e Brasil. Psicologia em Revista, 23(2), 573-588.

Calazans, G. J., Pinheiro, T. F., \& Ayres, J. R. C. M. (2018). Vulnerabilidade programática e cuidado público: Panorama das políticas de prevenção do HIV e da Aids voltadas para gays e outros HSH no Brasil. Sexualidad, Salud y Sociedad, 29, 263-293.

Calderaro, F. (2011). Políticas de saúde voltadas às lésbicas: Um estudo sobre as possibilidades de reverter um quadro histórico de invisibilidade (Dissertação de mestrado em Psicologia Social, Pontifícia Universidade Católica de São Paulo (PUC-SP), São Paulo).

Cochran, S. D., \& Mays, V. M. (2012). Risk of Breast Cancer Mortality Among Women Cohabiting with Same Sex Partners: Findings from the National Health Interview Survey, 1997-2003. Journal of Women's Health, 21(5), 528-533.

Curmi, C., Peters, K., \& Salamonson, Y. (2014). Lesbians' attitudes and practices of cervical cancer screening: a qualitative study. BCM Women's Health, 14(153), 1-9.

Decreto n. 9.795, de 17 de maio de 2019. (2019). Atualização da estrutura regimental do Ministério da Saúde. Diário Oficial da União. Brasília, DF.

Facchini, R. (2003). Movimento homossexual no Brasil: Recompondo um histórico. Cadernos AEL, 10(18/19). Disponível em https://www.ifch.unicamp.br/ojs/index.php/ ael/article/view/2510/1920

Facchini, R. (2008). Entre umas e outras: Mulheres, homossexualidades e diferenças na cidade de São Paulo (Tese de doutorado em Ciências Sociais, Instituto de Filosofia e Ciências Humanas, Universidade Estadual de Campinas, Campinas).

Facchini, R., \& Barbosa, R. M. (2006). Dossiê Saúde das mulheres lésbicas: Promoção da equidade e da integralidade. Belo Horizonte: Rede Feminista de Saúde.

Fernandes, M. (2018). O movimento das mulheres lésbicas feministas no Brasil. Revista Cult, 235, [s.p.]. Disponível em https://revistacult.uol.com.br/home/ mulheres-lesbicas-feministas-brasil/

Fernandes, M., Soler, L. D., \& Leite, M. C. B. P. (2018). Saúde das mulheres lésbicas e atenção à saúde: Nem integralidade, nem equidade diante das invisibilidades. Revista Bis, 19(2), 37-46.

Gonçalves, R., \& Abreu, S. (2018). Do plano nacional de políticas para as mulheres ao "machistério" de Temer. Revista de Políticas Públicas, 22 (2), 1-19.

Harding, S. (1993). A instabilidade das categorias analíticas na teoria feminista. Revista Estudos Feministas, 1(1), 7-31.

Lei n. 8.080, de 19 de setembro de 1990. (1990). Dispõe sobre as condições para a promoção, proteção e recuperação da saúde, a organização e funcionamento dos serviços correspondentes e dá outras providências. Diário Oficial da União. Brasília, DF.

Machado, C. V., Lima, L. D., \& Baptista, T. W. F. (2017). Políticas de saúde no Brasil em tempos contraditórios: Caminhos e tropeços na construção de um sistema universal. Cadernos de Saúde Pública, 33(2), 143-161.

Martinho, M. (2006). Década de 80: Início da organização lésbica no Brasil. Lesbianismo Erudito [Blog], São Paulo. Disponível em http://coletaneapratica.blogspot.com/2011/07/miriam-martinho.html

Meinerz, N. E. (2011). Mulheres e masculinidades - Etnografia sobre afinidades de gênero no contexto de parcerias homoeróticas entre mulheres de grupos populares em Porto 
Alegre (Tese de doutorado em Antropologia Social, Instituto de Filosofia e Ciências Humanas, Universidade Federal do Rio Grande do Sul, Porto Alegre).

Pamplona, R. S., \& Dinis, N. F. (2013). Probabilidade: Discursos produzidos sobre a bissexualidade. Comunicações, 2, 97-112.

Pompeu, F. (2001). Direitos que não podem calar. Jornal da RedeSaúde, 24, 35-41.

Prins, B., \& Meijer, I. (2002). Como os corpos se tornam matéria: entrevista com Judith Butler. Revista Estudos Feministas, 10(1), 155-167.

Rede Feminista de Saúde (2008). Marcos da saúde das mulheres, dos direitos sexuais e direitos reprodutivos. Material produzido a partir do 10 ㅇ Encontro Nacional da Rede Feminista de Saúde. Porto Alegre, RS, Brasil.

Rede Feminista de Saúde (2015). Posições Políticas. Publicação Especial da Gestão 2011/2015. Florianópolis, SC, Brasil, 11.

Resolução n. 614, de 15 de fevereiro de 2019. (2019). O Conselho Nacional de Saúde aprova diretrizes referentes à Programação Anual de Saúde e o Projeto de Lei de Diretrizes Orçamentárias da União para 2020.

Rodrigues, J. L. (2018). Lésbicas e mulheres bissexuais: Uma leitura interseccional do cuidado à saúde. (Tese de doutorado em Ciências, Programa de Saúde Coletiva, Faculdade de Medicina, Universidade Federal de São Paulo, São Paulo).

Silva, M. J. M. (2015). Saúde das mulheres lésbicas no Brasil. Anais do XX Seminário de Pesquisa do CCSA - "Construindo saberes para a promoção do desenvolvimento e da democracia. Universidade Federal do Rio Grande do Norte (UFRN).

Soares, S. F., Peres, M. C. C., \& Dias, M. C. M. (2017, setembro). Saúde e Sobrevivência Lésbica: Uma questão de saúde pública. Comunicação Oral apresentada no V Seminário Internacional Enlaçando Sexualidades, Rio de Janeiro, RJ, Brasil.

Watermann, L., \& Voss, J. (2015). HPV, cervical cancer risks, and barriers to care for lesbian women. The Nurse Practitioner, 40(1), 46-53.

Wittig, M. (2012). Ninguém nasce mulher. Trad. Hurrah, um grupelho eco-anarquista e Coletivo Bonnot, Departamento de Terrorismo Performático de Gênero.

VI Seminário Nacional de Lésbicas (Senale). (2006). Movimento de Mulheres Lésbicas como Sujeito Político: Poder e Democracia - Relatório Final. Recife, PE: Grupo Curumin, 68.

Recebido em: 30/07/2019

última revisão: 30/09/2019

Aceite final: 23/11/2019

\section{Sobre os autores:}

Isabela Guimarães Alves: Psicóloga. Especialista em Oncologia pela Universidade Federal de Minas Gerais (UFMG), Belo Horizonte, MG. Bolsista de Mestrado Capes, pesquisadora do Núcleo de Direitos Humanos e Cidadania LGBT (NUH/UFMG). Pesquisa nos campos de gênero e sexualidade, saúde e direitos humanos. E-mail: alves.isabelag@gmail.com, Orcid: https://orcid.org/0000-0001-9358-8525

Lisandra Espíndula Moreira: Doutora em Psicologia pela Universidade Federal de Santa Catarina (UFSC). Mestre em Psicologia Social e Institucional pela Universidade Federal do Rio Grande do Sul (UFRGS). Psicóloga pela UFRGS. Professora no curso de Direito e na Pós-Graduação em Psicologia da UFMG. E-mail: lisandra.ufmg@gmail.com, Orcid: https://orcid.org/0000-0001-9356-3416 
Marco Aurélio Máximo Prado: Pós-doutor pela Universidade de Massachusetts/Amherst. Doutor em Psicologia Social pela Pontifícia Universidade Católica (PUC). Professor do Programa de Pós-Graduação em Psicologia na Universidade Federal de Minas Gerais (UFMG). Coordenador do Núcleo de Direitos Humanos e Cidadania LGBT (NUH/UFMG). Pesquisador pela Fundação de Amparo à Pesquisa do Estado de Minas Gerais (Fapemig) e pelo Conselho Nacional de Desenvolvimento Científico e Tecnológico (CNPq). E-mail: mamprado@gmail.com, Orcid: https://orcid.org/0000-0002-3207-7542 
